(CMV) in the pulmonary tissue of patients with AIDS $^{8}$ and human herpes virus 6 associated interstitial pneumonitis in bone marrow transplant patients. ${ }^{9}$ Although a number of features of this suggest that EBV may be pathogenic, it is important to note that, because of the presence of immunosuppression, it remains possible that the EBV replication was coincidental rather than causal to the graft failure.

The histological features of the open lung biopsy specimen suggest that neither obliterative bronchiolitis nor bronchiolitis obliterans organising pneumonia were the cause of the graft failure. The presence of pyrexia in association with an eosinophilic infiltrate, and the demonstration of EBV replication which responded to ganciclovir, implicates EBV in the aetiology of the graft failure. In view of this case and recent reports documenting EBV within lung graft tissue, ${ }^{10} \mathrm{EBV}$ may be an important occult pathogen in the setting of lung graft failure.

1 Burke CM, Theodore J, Baldwin JC, Tazelaar HD, Morris $\mathrm{AJ}, \mathrm{McG}$ regor C, et al. Twenty eight cases of human heart/ lung transplantation. Lancet 1986; i:517-9.
2 Stewart JP, Arrand JR. Expression of the Epstein-Barr virus latent membrane protein in nasopharyngeal carcinoma biopsy specimens. Hum Pathol 1993;24:239-42.

3 Hoffman GJ, Lazarowitz SG, Hayward SD Monoclonal antibody against a 250000 -dalton glycoprotein of EpsteinBarr virus identifies a membrane antigen and a neutralising antigen. Proc Natl Acad Sci USA 1980;77:2979-83.

4 Steward S, Carey N. The pathology of heart and heart/lung transplantation - an update. $\mathcal{F}$ Clin Pathol 1991;44:803-11.

5 Yousem SA, Berry GJ, Brunt EM, Chamberlain D, Hruban $\mathrm{RH}$, Sibley RK, et al. A working formulation for the standardisation of rejection in the diagnosis of heart/lung rejection; lung rejection study group. $\mathcal{F}$ Heart Transplant 1990;9:593-601.

6 Granton J, de Hoyas A, Chamberlain D, Weisbrod G, Herman S, Winton T, et al. Bronchiectasis is related to the presence of obliterative bronchiolitis in lung transplant recipients. Am Rev Respir Dis 1992;142:A700.

7 Hotchin NA, Crawford DH. The diagnosis of Epstein-Barr virus-associated disease. In: Morgan-Capner P, ed. Current topics in clinical vimology. Salisbury, Wiltshire: Laverham topics in clinical virolo

8 Millar AB, Patou G, Miller RF, Grundy JE, Katz DR, Weller IV, et al. Cytomegalovirus in the lungs of patients with AIDS. Respiratory pathogen or passenger? Am Rev Respir Dis 1990;141:1474-7.

9 Carrigan DR, Drobyski WR, Russler SK, Tapper MA, Know $\mathrm{KF}$, Ash RC. Interstitial pneumonitis associated with human herpesvirus-6 infection after marrow transplantation. Lancet 1991;338:147-9.

10 Hoffman DG, Gedebou M, Jimenez A, Nichols WS, Marchevsky A. Detection of Epstein-Barr virus by polymerase chain reaction in transbronchial biopsies of lung transplant recipients: evidence of infection? Mod Pathol 1993;6: 555-9.

\section{Pregnancy following a single lung transplant}

\author{
Diane Parry, Andrew Hextall, \\ V P Robinson, N R Banner, M H Yacoub
}

\begin{abstract}
Successful pregnancy in a single lung transplant recipient has not been reported previously. The long term effect of pregnancy on graft function and management of deteriorating pulmonary function is not defined. This case describes the management, outcome, and problems encountered when a single lung transplant recipient developed a progressive deterioration in pulmonary function during pregnancy, attributed to accelerated obliterative bronchiolitis.
\end{abstract}

(Thorax 1996;51:1162-1164)

Harefield Hospital NHS Trust, Harefield, UK

D Parry

N R Banner

M H Yacoub

Hillingdon Hospital NHS Trust, Uxbridge, Middlesex UB8 3NN, UK

A Hextal

P Robinson

Correspondence to: Dr D Parry.

Received 22 February 1996 Accepted for publication

2 May 1996
Keywords: lung transplantation, pregnancy, obliterative bronchiolitis.

There have been a number of reports of pregnancy with successful outcome following solid organ transplantation. Most of the information available pertains to renal and heart transplant recipients. ${ }^{12}$ With improving survival and functional status after transplantation, more women are able to consider the possibility of starting a family. Single lung transplantation was first performed successfully in $1983 .^{3}$ The indications are usually restrictive or obstructive pulmonary disease. This report describes the successful outcome of a pregnancy in a woman following single lung transplantation.

\section{Case report}

The patient was a 31 year old white nonsmoker who first presented in 1988 at the age of 24 with breathlessness and a dry cough. She had suffered from Raynaud's phenomenon since childhood and had two grand mal fits during adolescence, the last being 10 years previously. A cerebral computed tomographic scan had been normal. A diagnosis of fibrosing alveolitis was made on open lung biopsy and treatment consisted of high dose prednisolone and cyclophosphamide. She continued to receive sodium valproate for her epilepsy.

Her respiratory condition gradually deteriorated and she developed cyclophosphamide related cystitis. She was accepted for a single lung transplant and placed on the waiting list in June 1992. At that stage she was receiving prednisolone $15 \mathrm{mg}$ daily and her forced expiratory volume in one second $\left(\mathrm{FEV}_{1}\right)$ was $1.06 \mathrm{l}$ (36\% predicted), forced vital capacity (FVC) 1.171 .

In April 1993 she underwent left single lung transplantation. The donor was a 28 year old female non-smoker with no history of cardiopulmonary disease. Total ischaemic time for the procedure was five hours. In the early postoperative period the patient required one course of methylprednisolone ( $1 \mathrm{~g}$ for three days) for acute rejection, and antibiotics for Staphylococcus aureus cultured from sputum. She made a complete recovery.

In April 1994 her exercise tolerance was excellent. She led a full active life and planned marriage. At her annual assessment $\mathrm{FEV}_{1}$ was 


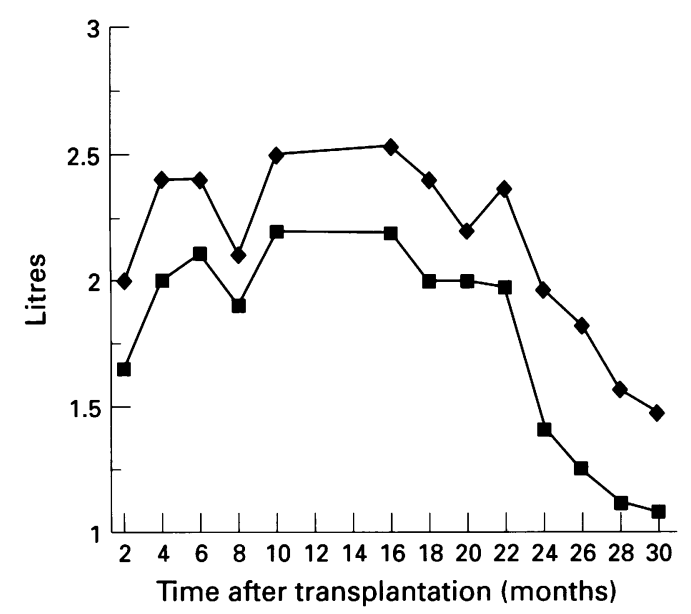

Figure 1 Lung function following transplantation. $\square=F E V_{1} ; \diamond=F V C$.

2.21 (75\% predicted) and FVC 2.51 (74\% predicted). Immunosuppression consisted of triple therapy with whole blood cyclosporin levels of $150-250 \mathrm{ng} / \mathrm{ml}$ (parent compound), azathioprine $1 \mathrm{mg} / \mathrm{kg}$, and prednisolone $(8 \mathrm{mg}$ at one year).

In October 1994 the patient presented with a 10 week history of vomiting and deterioration in respiratory function tests. She also complained of suprapubic discomfort. A suprapubic mass was found on clinical examination and an ultrasound scan was therefore performed. This revealed a single live fetus of approximately 15 weeks gestation. At that time cyclosporin levels were $200 \mathrm{ng} / \mathrm{ml}$ and the spirometric parameters were stable with $\mathrm{FEV}_{1} 2.11$ (73\% predicted). Bronchoscopy was performed and Pseudomonas aeruginosa was grown from the bronchoalveolar lavage fluid. Appropriate antibiotics were commenced.

Her blood pressure at her first antenatal visit was $110 / 70 \mathrm{~mm} \mathrm{Hg}$ and urinalysis was normal. Serum screening for Down's syndrome was performed with $\alpha$-fetoprotein and human chorionic gonadotrophin, and this gave a combined risk of 1 in 45 . Amniocentesis at 18 weeks revealed a normal fetal karyotype. A detailed fetal anomaly ultrasound scan at 19 weeks confirmed normal anatomy. Serial ultrasound scans were performed from 23 weeks and confirmed normal fetal growth. She was admitted to hospital at 26 weeks with a small painless antepartum haemorrhage for which no cause was found.

Respiratory function tests were performed daily by the patient and monthly in the lung function laboratory. They demonstrated a decline despite stable immunosuppression (fig 1). At 34 weeks gestation $\mathrm{FEV}_{1}$ had fallen to 1.481 (50\% predicted) and FVC to $1.921(57 \%$ predicted), and the patient complained of breathlessness. She was admitted and given intravenous methylprednisolone $500 \mathrm{mg}$ for three days. The lung function did not improve and a bronchoscopy was performed. No growth was found on culture of the bronchoalveolar lavage fluid. No biopsy specimens were taken. She was commenced on oral prednisolone $1 \mathrm{mg} / \mathrm{kg}$ tailing to $0.2 \mathrm{mg} / \mathrm{kg}$. She remained an inpatient and daily urinalysis revealed $1+$ of proteinuria. Her blood pressure rose to a maximum of $130 / 90 \mathrm{~mm} \mathrm{Hg}$ and the lung function continued to decline.

Elective lower segment Caesarean section was performed at 38 weeks gestation under a combined epidural-spinal anaesthetic and a healthy male infant was delivered with a birth weight of $2.56 \mathrm{~kg}$. He was bottlefed and at nine months is thriving and developing normally.

There were no postoperative complications. Following delivery there was symptomatic improvement but her spirometric values continued to decline and at eight weeks postpartum the $\mathrm{FEV}_{1}$ was 1.261 and FVC 1.831. She was hypertensive and amlodipine $5 \mathrm{mg}$ was started with good effect. The patient and her husband have used the sheath and spermicidal jelly for contraception.

In view of the continuing deterioration she was converted to tacrolimus but, despite adequate blood levels $(10-15 \mathrm{mg} / \mathrm{ml})$, her lung function tests continued to decline so she underwent total lymphoid irradiation following which her condition has stabilised.

The patient continues to lead an independent life and is able to care for her child.

\section{Discussion}

Little information is available about pregnancy in single lung transplant recipients and this is the first case to be reported.

Pregnancy in "normal" women does not usually result in major changes in respiratory function tests and any decline in those of lung transplant recipients should therefore be viewed with suspicion. There should be a low threshold for the diagnosis of graft dysfunction, but management is hampered by a reluctance to perform chest radiography and invasive procedures such as bronchoscopy and transbronchial biopsies during pregnancy.

In renal transplant recipients changes in cyclosporin levels (caused by increasing blood volume, reduced haematocrit, and impairment of hepatic clearance) have been recorded in pregnancy. ${ }^{45}$ Cyclosporin levels must be monitored carefully and doses adjusted accordingly to maintain therapeutic levels. Cyclosporin nephrotoxicity, which may be present before pregnancy, and hypertension are prevalent in transplant recipients and may predispose to pre-eclamptic toxaemia (PET). ${ }^{6}$

The effect of immunosuppressive drugs on the fetus and neonate have been studied in the children of renal and heart transplant recipients. There appears to be no significant effect on fetal immunity ${ }^{7}$ and there is low risk of teratogenicity with these agents. ${ }^{8}$ However, the incidence of prematurity and fetal growth retardation in children of renal transplant recipients is high. ${ }^{19}$

Chronic rejection/obliterative bronchiolitis is a serious long term complication of lung transplantation. We do not know if the risk is increased in pregnancy or the postpartum period. More aggressive investigation and immunosuppression therapy may be required to reduce long term graft dysfunction, but this has to 
be balanced against the attendant risks of life threatening infections and possible treatment with antibiotic regimens that may be teratogenic. The five year survival rate following single lung transplantation is $40 \%,{ }^{10}$ and there is a significant risk that a mother will not live to see her child reach maturity.

1 Radomiski JS, et al. Outcome of 500 pregnancies in 335 female kidney, liver and heart transplant recipients. Transplant Proc 1995;27:1089-90.

2 Lowerskin BR, et al. Successful pregnancy and vaginal delivery after heart transplantation. Am $f$ Obstet Ginecol $1988 ; 158: 589-90$.
3 Toronto Lung Transplant GPs. Unilateral lung transplantation for pulmonary fibrosis. $N$ Engl $F \mathrm{Med} 1986$; 314:1140-5.

4 Biesenbach $\mathrm{G}$, et al. Cyclosporin requirement during pregnancy in renal transplant recipients. Nephrol Dial Transplant 1989;4:667-9.

5 Low RJ, Scott JR. Pregnancy following renal transplantation. Clin Obstet Gynecol 1985;28:339-50.

6 Cunningham FG, MacDonald PC, Gant NF, Williams FG. Obstetrics. 18th edn. Newark: Appleton, Lange, 1989.

7 Rose ML, et al. Analysis of $T$ cell subpopulations and cyclosporin levels in the blood of two neonates born to immunosuppressed heroung transplant recipients. Transplantation 1989;48:223-6.

8 Bumgardner GL, Matas AJ. Transplantation and pregnancy. Transplant Proc 1992;6:139-62.

9 Prisu Y, Van Liede M, Ghysen J, et al. Retardation of fetal growth in patients receiving immunosuppressive drugs. $N$ Engl 7 Med 1985;313:328.

10 International Society for Heart and Lung Transplantation. Registry data. 12th official report. Vol 14 . No 5 . Sept/Oct 1995.
Paul A Corris

These three case reports all have lung transplantation as a common unifying theme but otherwise appear at first sight to comprise a heterogeneous collection. Each case, however, provides useful information regarding the management and understanding of lung disease in general. The careful study of patients undergoing lung transplantation for respiratory disease provides the potential for a rich source of information of help in our understanding of the basic mechanisms of lung diseases and their management that greatly extends beyond problems of alloreactivity alone. This is an exciting new avenue of research that is currently under extensive study in lung transplant centres worldwide.

Robinson et al describe a patient who underwent right single lung transplantation for severe acute interstitial pneumonia which subsequently improved in his native left lung after surgery. The patient had atypical clinical and radiological features of idiopathic pulmonary fibrosis and a lack of positive autoantibodies or raised systemic inflammatory markers. Failure to respond to high dose steroid therapy appeared to be the feature which prompted the decision to perform an open lung biopsy and, of course, the indications as to when and by which means lung biopsy specimens should be taken in patients presenting with diffuse parenchymal lung disease remains controversial. The improvement in radiographic appearances of the native left lung after right single lung transplantation is intriguing and contrasts markedly with our own experience of single lung transplantation in patients with idiopathic pulmonary fibrosis. We have never recognised improvements in the native lung in 28 such patients. In fact, the lung is frequently seen to continue to shrink and end up completely consolidated. Although the im-

provement seen in this case may in part be explained by the transplantation allowing time for spontaneous resolution to occur, it is more tempting to ascribe it to the effects of immunosuppression. We are not told whether the patient had any episodes of rejection treated by pulsed methylprednisolone, but he certainly received immunosuppression comprising azathioprine, cyclosporin, and prednisolone. Important messages relate to the need to ensure that best medical treatment has been given prior to referral for transplantation and the appropriate use of a single lung graft compared with bilateral grafts in this case, in view of the subsequent events. The identification of a specific histological picture that is distinct from usual interstitial pneumonia underlines the value of open lung biopsies in atypical cases and should alert physicians to the need for intensification of immunosuppression in those patients with acute interstitial pneumonia who fail to respond to conventional therapy.

Egan et al describe a patient who developed irreversible graft dysfunction with alveolar fibrosis associated with Epstein-Barr virus (EBV) infection on immunocytochemistry after heart lung transplantation. A specific antigen diagnostic of EBV replication was identified, although EBV latent membrane protein and nuclear antigen 2 were negative. The interpretation that EBV replication was the cause of graft failure and fibrosis is, of course, speculative and it remains possible that the EBV replication was coincidental. Nevertheless, there is current interest in the potential relationship between EBV and idiopathic lung fibrosis in general and this case at least provides some further evidence of the fibrogenic potential of EBV. It would have been both interesting and informative if the tissue had been examined for the presence of proliferative cytokines such as TGF- $\beta$. We have had the opportunity to study lung biopsy tissue from a
Thoracic Medicine, Freeman Hospital and University of Newcastle upon Tyne, NE7 7DN, UK P A Corris 